Titulo do Trabalho

\title{
SIG COMO FERRAMENTA DE MAPEAMENTO DAS FORMAS DE USO E OCUPAÇÃO DO SOLO NA MICROBACIA HIDROGRÁFICA DO CÓRREGO MONTE BELO - BOTUCATU/SP
}

Nome do Autor (a) Principal

\section{Ana Clara Barros}

Nome (s) do Coautor (a) (s)

Gabriel Rondina Pupo da Silveira; Aline Kuramoto Gonçalves

Nome (s) do Orientador (a) (s)

Yara Manfrin Garcia

Instituição ou Empresa

Universidade Estadual Paulista "Júlio de Mesquita Filho" - UNESP/FCA, Botucatu

E-mail de contato

anaclara_inha@hotmail.com

Palavras-chave

Geotecnologia. Sensoriamento Remoto. Meio Ambiente.

\section{INTRODUÇÃO}

No Brasil, a unidade física adotada na legislação para o gerenciamento de recursos hídricos é a de bacia hidrográfica que constitui um princípio básico para a implementação da gestão dos recursos hídricos, sendo que tal denominação também é utilizada em outros países (GARCIA, 2011). 
A bacia hidrográfica, dentro de uma visão integrada, deve ser a unidade de caracterização, diagnóstico, planejamento e gestão ambiental, com vistas ao desenvolvimento regional sustentável, pois os impactos ambientais podem ser mensurados e corrigidos mais facilmente. Assim, a água vem a ser um elemento integrador dos fenômenos físicos (ARAÚJO; TELES; LAGO, 2009).

Santana (2004) menciona que as bacias hidrográficas podem ser desmembradas em um número qualquer de sub-bacia, dependendo do ponto de saída considerando a drenagem ao longo do eixo-tronco ou canal coletor. Cada bacia hidrográfica interliga-se com outra, de ordem hierárquica superior, construindo em relação à última, uma sub-bacia.

Outro conceito importante atribuído a microbacias é o ecológico, que considera a menor unidade do ecossistema onde pode ser observada a delicada relação de interdependência entre os fatores bióticos e abióticos, sendo que perturbações podem comprometer a dinâmica de seu funcionamento. Esse conceito visa à identificação e o monitoramento de forma orientada dos impactos ambientais (MOSCA, 2003; LEONARDO, 2003).

O estudo de microbacias hidrográficas e dos aspectos ambientais nela inseridas pressupõe uma série de conhecimentos e informações que precisam ser trabalhados de maneira mais ágil, fácil e rápida, destacando assim as novas tecnologias. Assim, para Fitz (2008), as geotecnologias trazem avanços significativos no desenvolvimento de pesquisas, em ações de planejamento, processos de gestão, manejo e em tantos outros aspectos.

De acordo com Rosa (2005), o Sensoriamento Remoto e os Sistemas de Informações Geográficas são instrumentos poderosos no levantamento, mapeamento e monitoramento dos recursos naturais.

A característica principal dos SIGs é a localização geográfica do fenômeno, baseando-se no sistema de coordenadas geográficas sobre o qual o registro é geocodificado, permitindo assim, a expressão da territorialidade e da topologia dos dados ambientais (TORNERO, 2000).

Para Câmara (1993), os SIGs são sistemas cujas principais características são: integrar, numa única base de dados, informações espaciais provenientes de 
dados cartográficos, dados de censo e de cadastro urbano e rural, imagens de satélites e modelos numéricos de terrenos; combinar as várias informações, através de algoritmos de manipulação, para gerar mapeamentos derivados; consultar, recuperar, visualizar e imprimir o conteúdo da base de dados geocodificados.

Para Calijuri et al. (1994), o uso do IDRISI, além dos aspectos de agilidade, compatibilização de informações de diferentes fontes, serve para implantar um banco de dados informatizado e atualizado, contendo a evolução de eventos no espaço e no tempo; além de permitir que o banco de dados seja permanentemente alimentado e atualizado com novas informações.

Segundo Florenzano (2011), sensoriamento remoto pode ser definido como a tecnologia que permite obter imagens - e outros tipos de dados - da superfície terrestre, por meio da captação e do registro da energia refletida ou emitida pela superfície.

Para concluir, Garcia (2014) enfatiza que os instrumentos de sensoriamento remoto e os Sistemas de Informações Geográficas apresenta-se de maneira satisfatória, gerando informações que subsidiam a análise mais completa da área de estudo e desta forma, pode-se enfatizar que com a grande expansão das atividades humanas sobre o ambiente, a demanda por tecnologias ambientais tem sido cada vez mais procurada.

O monitoramento ambiental, através do acompanhamento da dinâmica do uso e ocupação do solo, possibilita a atuação racional do homem sobre o ambiente. Assim, os efeitos prejudiciais ao meio físico diminuem, uma vez que o acompanhamento desta dinâmica permite o diagnóstico das mudanças ocorridas sobre o meio ambiente (SILVA; FRANÇA, 2013).

\section{OBJETIVO GERAL}

Considerando a importância do mapeamento do uso e ocupação do solo como forma de conhecer o espaço geográfico e definir ações de planejamento, o presente trabalho objetivou realizar o levantamento e mapeamento do uso e 
ocupação do solo na microbacia hidrográfica do córrego Monte Belo, localizado no município de Botucatu/SP.

\section{OBJETIVOS ESPECÍFICOS}

Para o mapeamento do uso e ocupação do solo na microbacia hidrográfica do córrego Monte Belo faz-se necessário o conhecimento e utilização de técnicas de Sensoriamento Remoto e Sistema de Informação Geográfica (SIG).

\section{METODOLOGIA}

Os pontos de controle (coordenadas) para o georreferenciamento e os pontos de máxima altitude para digitalização do limite da microbacia tiveram como base a Carta Planialtimétrica em formato digital, editada pelo Instituto Brasileiro de Geografia e Estatística - IBGE (1973), folha de Botucatu (SF-22-R-IV-3), em escala 1:50000.

Utilizou-se a imagem de satélite digital, bandas 3, 4 e 5 do sensor "Thematic Mapper" do LANDSAT - 5, da órbita 220, ponto 76, quadrante A, passagem de 2011 , escala 1:50000.

O Sistema de Informações Geográficas (SIG) utilizado foi o "software" IDRISI Selva para o georreferenciamento e processamento das informações georreferenciadas, na conversão dos dados vetoriais em imagem raster e na elaboração do mapa final do uso da terra. O "software" CartaLinx foi utilizado na digitalização do limite da microbacia e das classes de uso e ocupação do solo.

A delimitação da área da microbacia do Córrego Monte Belo - Botucatu (SP) foi realizado através da carta planialtimétrica, seguindo os pontos mais elevados e tendo-se como base a definição de Rocha (1991) para bacia hidrográfica.

Na consequência, foi elaborada uma composição colorida com a combinação das bandas (obtida a partir da imagem de satélite digital) 3,4 e 5 , do sensor "Thematic Mapper" do LANDSAT - 5, da órbita 220, ponto 76 , quadrante A, 
passagem de 2011, escala 1:50000. A combinação destas bandas apresenta uma boa discriminação visual dos alvos, possibilitando a identificação dos padrões de uso da terra de maneira lógica. Esta composição apresenta os corpos d'água em tons azulados, as florestas e outras formas de vegetações em tons esverdeados e os solos expostos em tons avermelhados.

Para a composição, foi realizado o processo de composição da imagem RGB (Red Green Blue), utilizando-se da função "Composite" do menu "Display" do IDRISI.

A seguir, foi realizado o georeferenciamento da composição, utilizando-se para isso o módulo Reformat/Resample do SIG - IDRISI, sendo os pontos de controle obtido na carta planialtimétrica do IBGE, referente ao município de Botucatu. Para o georreferenciamento, também foi utilizado o sistema de coordenadas planas, projeção UTM, datum Córrego Alegre. Desta forma, foram determinadas as coordenadas de cada ponto e com estes dados foi gerado um arquivo de correspondência

Após o georreferenciamento foi feito o recorte da imagem através da opção "Reformat/Window" extraindo assim apenas a área da bacia.

Em seguida, no software CartaLinx, através do comando "File/ Image Conversion" buscou o arquivo georreferenciado e salvou, em seguida, em "File/New Coverage/Coverage Based Upon Bitmap" abriu o mesmo arquivo para começar o processo de delimitação dos elementos (limite e áreas de uso e cobertura). Para o limite e as áreas de uso e cobertura foram criados polígonos. Quanto a elaboração dos polígonos de uso e cobertura, criou-se uma tabela, através do menu "Tables/Add Fields" e em cada polígono colocou-se o número correspondente aos elemento (ex: Mata $=1$, Área Urbana $=2$, e assim sucessivamente).

Posteriormente, exportou-se estes arquivos criados para o IDRISI. A tabela de uso e ocupação também foi exportada e transformada para raster. Através do comando “Area” do menu "Database Query", pertencente ao módulo "Analysis", foram determinadas as áreas e as porcentagens de cada uso. 


\section{RESULTADO (S)}

Por meio da utilização de técnicas de sensoriamento remoto e Sistema de Informação Geográfica foi possível a análise do uso e ocupação do solo possibilitando uma visão holística da microbacia hidrográfica.

A Figura 1 é resultado da primeira etapa para a identificação das classes de uso e ocupação do solo que foi gerada a partir da composição das bandas da imagem de satélite.

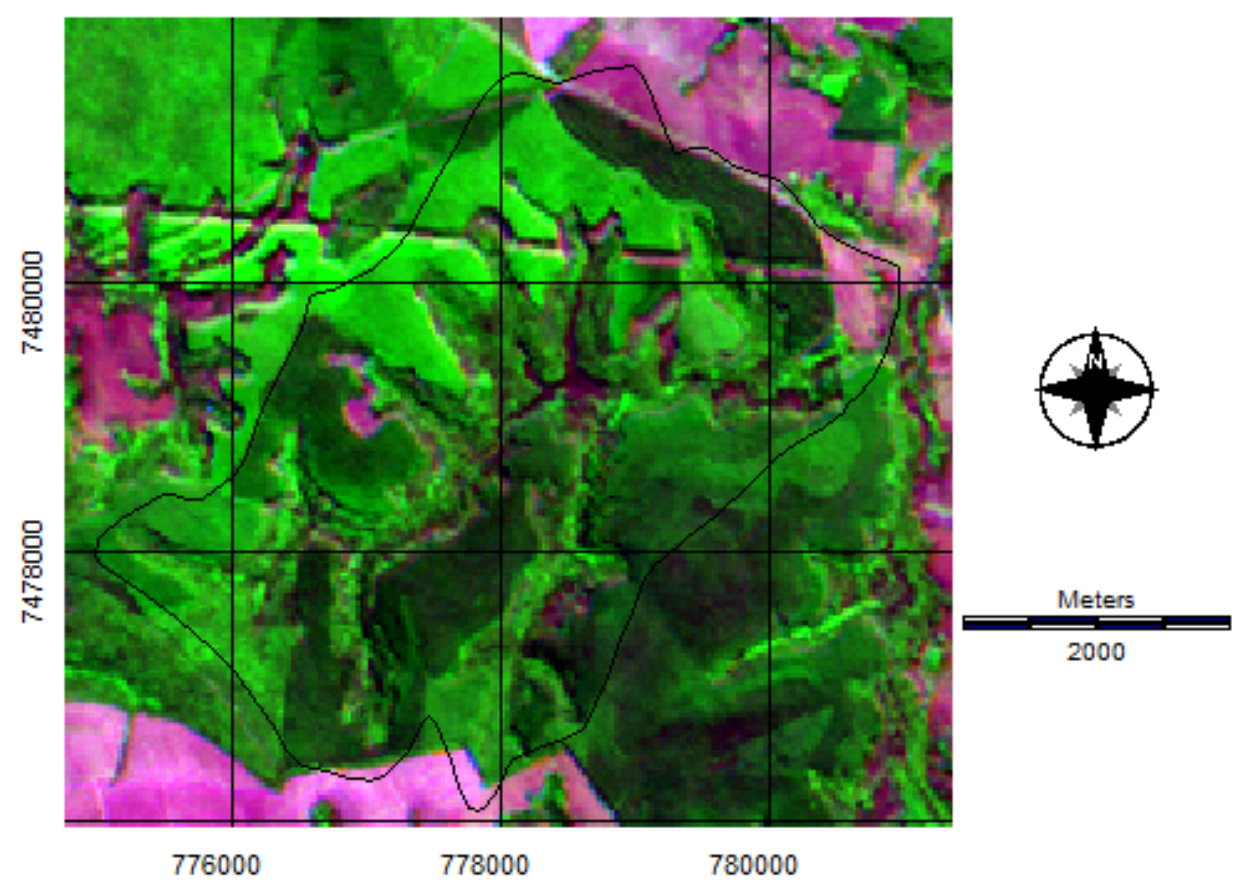

Figura 1 - Composição das bandas da imagem de satélite na área de estudo.

O levantamento do uso do solo, em uma determinada região, torna-se um aspecto de interesse fundamental para a compreensão dos padrões de organização do espaço já que o conhecimento das alterações ambientais, provocadas pela ação antrópica, possibilita uma visão dos problemas existentes e produz subsídios para gestão dos recursos naturais (NARDINI, 2009). 
No mapeamento do uso e ocupação do solo na microbacia do córrego Monte Belo foram encontrados três (3) classes de uso divididas em: reflorestamento, mata ciliar e solo exposto, conforme Figura 2.

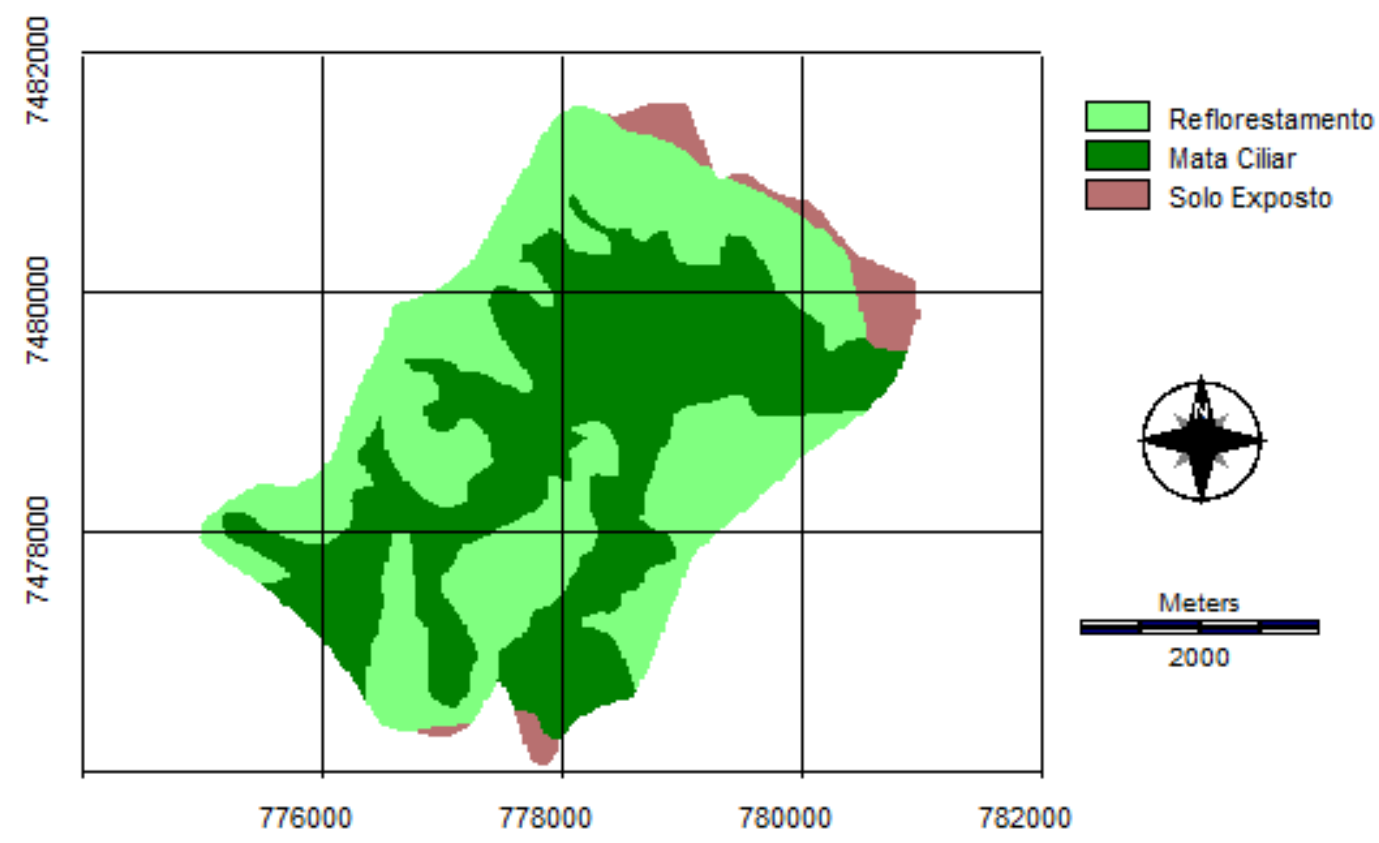

Figura 2 - Mapa de uso e ocupação do solo obtido por imagens de satélite de 2011.

Os resultados do uso da terra na microbacia do Ribeirão São Pedro Botucatu (SP) mostraram que o reflorestamento ocupa a maior parte da microbacia hidrográfica, sendo representado por 818,62ha $(48,23 \%)$.

A seguir, na Tabela 1, são apresentados os resultados de uso e ocupação do solo encontrados nas análises por meio de imagem de satélite.

Tabela 1 - Distribuição das áreas e porcentagens de uso e ocupação do solo em 2011.

\begin{tabular}{ccc}
\hline $\begin{array}{c}\text { Classes de Uso } \\
\text { do solo }\end{array}$ & \multicolumn{2}{c}{ Uso e Ocupação do Solo } \\
& ha & 2011 \\
Reflorestamento & 818,62 & $\%$ \\
& & 48,23
\end{tabular}




\begin{tabular}{ccc} 
Mata Ciliar & 804,12 & 47,38 \\
Solo Exposto & 74,48 & 4,39 \\
\hline Total & 1697,22 & 100 \\
\hline
\end{tabular}

É necessário enfatizar que o uso racional do solo deve ser baseado em atividades produtivas que considerem o potencial de terras para diferentes formas de uso, fundamentado no conhecimento das potencialidades e fragilidade dos ambientes, de forma a garantir a produção e reduzir os processos geradores de desequilíbrio ambiental, com base em tecnologias técnica e ambientalmente apropriadas (GEBLER; PALHARES, 2007).

\section{CONSIDERAÇÕES FINAIS}

A compreensão da dinâmica de ocupação do solo é fundamental para o estabelecimento de ações de planejamento para a microbacia hidrográfica. As classes de uso e ocupação do solo definidas no estudo da bacia hidrográfica em questão, estão relacionadas ao processo de conservação ambiental visto que apresenta uma grande porcentagem de mata ciliar. Porém, verificou-se que no uso predominantemente é o reflorestamento.

O uso de imagem de satélite, neste caso, do sensor TM/ Landsat 5 representou uma importante ferramenta para a realização deste trabalho permitindo o mapeamento eficaz da microbacia do córrego Monte Belo no qual apresenta subsídios para o planejamento do uso do solo. O Sistema de Informação Geográfica IDRISI Selva foi essencial na elaboração dos mapas possibilitando assim a compreensão desta dinâmica.

\section{REFERÊNCIAS}

ARAÚJO, E. P.; TELES, M. G. L.; LAGO, W. J. S. Delimitação das bacias hidrográficas da llha do Maranhão a partir de dados SRTM. In: Simpósio Brasileiro de Sensoriamento Remoto, XIV, 2009, Natal. Anais... Natal: 2009. p.4631-4638. 
CALIJURI, M. L.; CALIJURI, M. C.; TUNDISI, J. G.; RIOS, L. Implantação de um Sistema de Informação Geográfica na bacia hidrográfica do ribeirão e represa do Lobo (Broa) - Estado de São Paulo. In: GIS Brasil 94, Congresso e Feira para usuários de geoprocessamento. Anais... Curitiba: SAGRES, 1994. Cap.12, p.35-43.

CAMARA, G. Anatomia de Sistemas de Informações Geográficas: visão atual e perspectiva de evolução. In: ASSAD, E., SANO, E., ed. Sistema de informações geográficas: aplicações na agricultura. Brasília, DF, Embrapa, 1993.

FITZ, P. R. Geoprocessamento Sem Complicação. São Paulo: Oficina de Textos, 2008.

FLORENZANO, T. G. Iniciação em Sensoriamento Remoto. São Paulo: Oficina de Texto, 2011.

GARCIA, Y. M. Conflitos de uso do solo em APPs na bacia hidrográfica do córrego Barra Seca (Pederneiras/SP) em função da legislação ambiental.. Dissertação (Mestrado em Agronomia/Energia na Agricultura) - Faculdade de Ciências Agronômicas, Universidade Estadual Paulista. Botucatu-SP. UNESP. 2014.

GARCIA, Y. M. Aplicação do Código Florestal como Subsídio para o Planejamento Ambiental na Bacia Hidrográfica do Córrego do Palmitalzinho - Regente Feijó - São Paulo. Trabalho de conclusão (Bacharelado - Geografia) - Universidade Estadual Paulista, Faculdade de Ciências e Tecnologia - Presidente Prudente: [s.n], 2011, 145 f.

GEBLER, L.; PALHARES, J. C. P. (Eds.) Gestão ambiental na agropecuária. Brasília: Embrapa Informação Tecnológica. 2007. 310p.

INPE. Instituto Nacional de Pesquisas Espaciais - Divisão de Geração de Imagens (DGI-INPE). Catálogo de Imagens. Disponível em:<http://www.dgi.inpe.br/>. Acesso em: 05 jun. 2013.

IBGE. Instituto Brasileiro de Geografia e Estatística. Carta topográfica. Serviço gráfico do IBGE, 1973. Escala 1:50.000.

MOSCA, A. A. O. Caracterização hidrológica de duas microbacias visando a identificação de indicadores hidrológicos para o monitoramento ambiental de manejo de florestas plantadas. Dissertação (Mestrado em Recursos Florestais) - Escola Superior de Agricultura "Luis de Queiroz", Universidade de São Paulo, Piracicaba, 2003.

NARDINI, R. C. Determinação do conflito de uso e ocupação do solo em áreas de preservação permanente da microbacia do ribeirão Água-Fria, Bofete (SP), visando a conservação dos recursos hídricos. 2009. 61f. Dissertação (Mestrado em Agronomia/Irrigação e Drenagem)-Faculdade de Ciências Agronômicas, Universidade Estadual Paulista. Botucatu-SP. UNESP. 2009.

ROCHA, J. S. M. Manual de manejo integrado de bacias hidrográficas. ed. UFSM, Santa Maria, RS. 1991. 181p.

ROSA, R. Geotecnologias na Geografia Aplicada. Revista do Departamento de Geografia, 16, p. 8190, 2005. Disponível em:

<http://www.cchla.ufrn.br/geoesp/arquivos/artigos/ArtigoAmbienteGeotecnologias.pdf>. Acesso em: 20 maio 2013.

SANTANA, D. P. Manejo integrado de bacias hidrográficas. Sete Lagoas: EMBRAPA Milho e Sorgo - Documentos, 2004. 
SILVA, L. S.; FRANÇA, C. A. S. S. de M. SIG como ferramenta de mapeamento das formas de uso e ocupação do solo na APA Igarapé São Francisco, Rio Branco, Acre. In: XVI Simpósio Brasileiro de Sensoriamento Remoto - SBSR, Foz do Iguaçu, PR, Brasil, 13 a 18 de abril de 2013, INPE.

Anais...2013.

TORNERO, M. T. Análise ambiental através de sistema de informações geográficas

(SIG), como subsídio ao planejamento no município de Maringá - PR. Botucatu, 2000. 184p. Tese (Doutorado em Agronomia/Energia na Agricultura) - Faculdade de Ciências Agronômicas,

Universidade Estadual Paulista. 